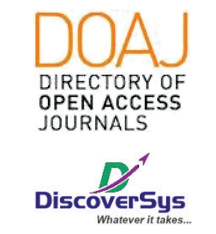

Published by DiscoverSys

\section{Hubungan kadar troponin I dan high-sensitivity troponin I dengan angiografi koroner pada pasien suspek coronary artery disease: studi di Rumah Sakit Umum Pusat dr.Wahidin Sudirohusodo Makassar-Indonesia tahun 2017}

\author{
Dessy Iriana, ${ }^{1 *}$ Asvin Nurulita, ${ }^{2}$ Darmawaty Rauf ${ }^{2}$
}

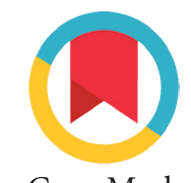

CrossMark

\title{
ABSTRACT
}

Background: Coronary artery disease (CAD) is a narrowing of blood vessels due to the formation of atherosclerotic plaques which can cause disruption of oxygen supply to the heart. High sensitivity troponin I (hs-Tnl) is a diagnostic tool for detecting heart disorders with minimal injury to the heart muscle.

Aim: The study aimed to compare and observe the relationship of troponin I (Tnl) and hsTnl with /RSUP dr.Wahidin Sudirohusodo Makassar.

Methods: The design of the study was cross-sectional study, using primary data of blood samples from 31 suspected CAD patients who underwent coronary angiography examination at RSUP Dr.Wahidin Sudirohusodo Makassar. Samples were taken from a population of subjects who met the inclusion criteria by using consecutive sampling technique in the period of September 2018. Statistical analysis were done using descriptive statistical calculations, frequency distribution and, Spearman's correlation test. The test results were considered significant if $p<0.05$.

Results: CAD was more common in men at the age of 50-69 years. Data analysis showed a significant correlation between Tnl, hsTnl, and the degree of stenosis $(p<0.001)$. The correlation coefficient of Tnl and degree of stenosis was 0.707 , hsTnl with degree of stenosis was 0.877 , and Tnl with hsTnl was 0.804 .

Conclusion: Higher levels of Tnl and hsTnl are related to the severity of stenosis in CAD.
'Program Pendidikan Dokter Spesialis Patologi Klinik, Fakultas Kedokteran Universitas Hasanuddin/RSUP dr.Wahidin Sudirohusodo Makassar, Indonesia 2Program Studi Patologi Klinik, Fakultas Kedokteran, Universitas Hasanuddin/ RSUP dr.Wahidin Sudirohusodo Makassar, Indonesia

*Korespondensi: Dessy Iriana; Program Pendidikan Dokter Spesialis Patologi Klinik, Fakultas Kedokteran Universitas Hasanuddin/RSUP dr.Wahidin Sudirohusodo Makassar, Indonesia; dessyiriana19@gmail.com

Diterima: $16-11-2018$ Disetujui: 13-05-2019 Diterbitkan: 01-08-2019
Keywords: CAD, Troponin I, High-sensitivity troponin I, Coronary angiography

Cite This Article: Iriana, D., Nurulita, A., Rauf, D. 2019. Hubungan kadar troponin I dan high-sensitivity troponin I dengan angiografi koroner pada pasien suspek coronary artery disease: studi di Rumah Sakit Umum Pusat dr.Wahidin Sudirohusodo Makassar-Indonesia tahun 2017. Intisari Sains Medis 10(2): 420-425. D0I: 10.15562/ism.v10i2.373

\section{ABSTRAK}

Latar Belakang : Coronary artery disease (CAD) adalah penyempitan pembuluh darah akibat pembentukan plak aterosklerotik yang dapat menyebabkan suplai oksigen ke jantung menjadi terganggu. Highsensitivity troponin I (hs-Tnl) adalah alat diagnostik untuk mendeteksi kelainan gangguan jantung dengan cedera minimal pada otot jantung. Penelitian ini bertujuan untuk membandingkan dan melihat hubungan antara troponin I (Tnl) dan hsTnl dengan angiografi koroner pada pasien suspek CAD.

Metode: Desain penelitian ini adalah cross sectional study menggunakan data primer dari sampel darah 31 pasien suspek CAD yang menjalani pemeriksaan angiografi koroner di RSUP Dr. Wahidin Sudirohusodo Makassar. Sampel diambil dari populasi subjek yang memenuhi kriteria inklusi dengan teknik consecutive sampling pada periode September 2018. Analisis statistik dilakukan dengan perhitungan statistik deskriptif, sebaran frekuensi, dan uji statistik Spearman's correlation. Hasil uji dianggap signifikan jika $p<0,05$.

Hasil: CAD lebih banyak ditemukan pada laki-laki dengan rentang usia 50-69 tahun. Dari hasil analisis didapatkan korelasi yang signifikan antara Tnl, hsTnl, dan derajat stenosis $(p<0,001)$. Koefisien korelasi (r) Tnl dengan derajat stenosis adalah 0.707, hsTnl dengan derajat stenosis adalah 0,877, dan Tnl dengan hsTnl adalah 0,804.

Kesimpulan: Semakin tinggi kadar Tnl dan hsTnl berhubungan dengan beratnya derajat stenosis pada CAD.

Kata Kunci : CAD, Troponin I, High-sensitivity troponin I, Angiografi koroner

Cite Pasal Ini: Iriana, D., Nurulita, A., Rauf, D. 2019. Hubungan kadar troponin I dan high-sensitivity troponin I dengan angiografi koroner pada pasien suspek coronary artery disease: studi di Rumah Sakit Umum Pusat dr. Wahidin Sudirohusodo Makassar-Indonesia tahun 2017. Intisari Sains Medis 10(2): 420-425. D0I: 10.15562/ism.v10i2.373 


\section{PENDAHULUAN}

Penyakit kardiovaskular adalah penyebab kematian global. Terhitung pada tahun 2013 terdapat lebih dari 17,3 juta kematian per tahun dan jumlah ini diperkirakan akan meningkat menjadi lebih dari 23,6 juta per tahun pada tahun 2030. Coronary artery disease $(\mathrm{CAD})$ adalah penyebab kematian paling umum, dimana CAD mencakup 45\% dari semua kematian akibat penyakit kardiovaskular. Terhitung 7,2 juta kematian per tahun atau $12 \%$ dari semua kematian di seluruh dunia disebabkan oleh CAD. Menurut data Riset Kesehatan Dasar (Riskesdas) tahun 2013, penyakit ini menunjukkan prevalensi tertinggi untuk penyakit kardiovaskular di Indonesia yang terdiagnosis dokter atau bergejala, yakni sebesar 1,5\%. Prevalensi tertinggi terdapat di Nusa Tenggara Timur $(4,4 \%)$, diikuti Sulawesi Tengah (3,8\%), Sulawesi Selatan (2,9\%), dan Sulawesi Barat (2,6\%). Berdasarkan hasil beberapa penelitian, prevalensi angina diperkirakan $12 \%$ - $14 \%$ pada pria dan $10 \%$ - $12 \%$ pada wanita berusia antara 65 dan 84 tahun. ${ }^{1-4}$

CAD adalah keadaan penyempitan pembuluh darah yang paling banyak terjadi akibat pembentukan plak aterosklerosis. Plak tersebut dapat disebabkan oleh peradangan, proliferasi sel otot, nekrosis, apoptosis, kalsifikasi, dan fibrosis di dinding arteri yang memicu perubahan penting pada dinding pembuluh darah koroner. CAD dapat muncul lebih awal, namun perkembangannya dari waktu ke waktu sangat tidak dapat diprediksi. Pembentukan aterosklerosis dapat berkembang pada tingkat yang bervariasi, dimulai dari penyempitan lumen yang dapat berkembang menjadi penyumbatan total yang terjadi secara mendadak. Penyumbatan total mendadak dapat terjadi akibat ruptur plak non-stenotik sehingga membentuk trombosis, dan pada akhirnya menyebabkan penurunan suplai darah yang membawa oksigen ke jantung. ${ }^{5,6}$

Troponin merupakan biomarker yang sangat sensitif dan spesifik pada nekrosis miokardium serta telah digunakan untuk mendiagnosis infark miokard akut. Troponin merupakan protein yang terdapat pada filamen tipis aparatus regulator otot bergaris. Troponin I (TnI) sendiri bekerja menghambat aktivasi ATPase aktomiosin. TnI memiliki tiga isoform yaitu satu isoform jantung dan dua isofornm otot skelet. Isoform TnI pada otot jantung menunjukkan perbedaan $40 \%$ dengan TnI pada otot skeletal. Perbedaan asam amino pada kedua otot tersebut dipakai sebagai dasar untuk pembuatan reagen yang spesifik pada otot jantung. ${ }^{7,8}$

Ketersediaan tes high-sensitivity troponin I (hs-TnI) memungkinkan untuk mendeteksi sirkulasi TnI otot jantung dalam konsentrasi yang lebih rendah. Pemeriksaan hs-TnI adalah tes diagnostik untuk mendeteksi kelainan gangguan jantung dengan cedera minimal pada otot jantung. Tingginya kadar hs-TnI yang bersirkulasi telah dikaitkan dengan prevalensi aterosklerosis koroner obstrukstif dan dengan kejadian efek samping kardiovaskular pada pasien CAD stabil atau pada populasi umum dan lansia. ${ }^{6}$

Baku emas untuk mendiagnosis CAD sampai saat ini adalah dengan pemeriksaan angiografi koroner. Pemeriksaan ini merupakan yang paling akurat mengidentifikasi penyempitan pembuluh darah yang berhubungan dengan proses aterosklerosis di arteri koroner jantung. CAD signifikan didefinisikan bila stenosis yang terjadi $\geq 70 \%$ dari diameter arteri epikardial utama walaupun hanya mengenai satu segmen, atau pada Left Main Disease (LMD) dengan setidaknya 50\% stenosis. Jantung memiliki tiga arteri koroner utama, sehingga diagnosis berdasarkan angiografi koroner disimpulkan dengan $\mathrm{CAD}$ one-vessel disease (CAD 1VD), CAD two-vessel disease (CAD 2VD) atau CAD three-vessel disease (CAD 3VD) tergantung pada jumlah pembuluh utama yang menyempit secara signifikan. Penderita mulai dapat menimbulkan gejala-gejala seperti nyeri dada atau sesak napas ketika penyempitan menjadi berat dan nyeri dada biasanya terjadi pada pasien dengan CAD yang menunjukkan stenosis setidaknya satu arteri epikardial. ${ }^{4,8-10}$

Penelitian Ford et al. (2016) menyimpulkan bahwa konsentrasi troponin mampu memprediksi gangguan koroner. Pengukuran troponin serial juga memiliki potensi besar untuk menilai risiko kardiovaskular. Penelitian Iribarren et al. (2016) di California menyimpulkan bahwa hs-TnI dapat memberikan informasi prognostik tambahan untuk insiden CAD di antara orang dewasa lanjut usia yang tidak bergejala. Tahhan et al. (2018) menyelidiki hubungan antara hs-TnI dengan tingkat keparahan CAD berdasarkan angiografi dan menyimpulkan bahwa kadar hs-TnI yang lebih tinggi berhubungan dengan risiko yang mendasari aterosklerosis koroner. ${ }^{6,11,12}$

Berdasarkan referensi yang sudah ada, peneliti tertarik untuk melakukan penelitian dengan membandingkan hubungan antara $\mathrm{TnI}$ dan hs-TnI dengan derajat stenosis melalui pemeriksaan angiografi koroner pada pasien suspek CAD di Pusat Jantung Terpadu (PJT) RSUP Dr.Wahidin Sudirohusodo Makassar, agar nantinya diharapkan dapat membantu dalam menegakkan diagnosis yang tepat sehingga pasien bisa mendapatkan perawatan dengan segera. 


\section{METODE}

Penelitian ini merupakan studi cross sectional dengan uji korelasi antara kadar TnI dan hs-TnI pada pasien CAD yang menjalani angiografi koroner di laboratorium kateterisasi jantung PJT RSUP Dr.Wahidin Sudirohusoso, Makassar.

Pasien suspek CAD sebanyak 31 orang dipilih sebagai subjek penelitian dengan consecutive sampling selama periode September 2018. Data yang dikumpulkan adalah data primer pada pasien suspek CAD yang menjalani angiografi koroner. Kriteria inklusinya adalah pasien suspek CAD yang bersedia menandatangani informed consent dan melakukan pemeriksaan angiografi koroner baik rawat jalan maupun rawat inap.

Analisis data dilakukan dengan menggunakan SPSS versi 22. Analisis statistik yang dilakukan adalah perhitungan statistik deskriptif, dan uji statistik Spearman's correlation. Hasil uji signifikan jika $\mathrm{p}<0,05$.

\section{HASIL}

Hasil analisis data berdasarkan pada karakteristik subjek penelitian ini disajikan sebagai berikut pada Tabel 1.

Nilai TnI dan hs-TnI sangat bervariasi, terlihat dari nilai standar deviasi (SD) yang lebih besar dari nilai mean (rerata). TnI mempunyai rerata $0,89 \pm 2,68$, sedangkan hs-TnI mempunyai rerata 3094,9 $\pm 9647,3$. Berdasarkan hal tersebut, dianggap bahwa sebaran data TnI dan hs-TnI tidak berdistribusi normal.

Dari 31 subjek yang diteliti didapatkan sebagian besar berjenis kelamin laki-laki (71\%), serta paling banyak pada kelompok usia antara 50-59 tahun $(38,7 \%)$ dan 60-69 tahun (32,3\%). Dari hasil pemeriksaan angiografi koroner, sebagian besar subjek menderita CAD 3VD (35,5\%).

Hasil uji menunjukkan terdapat perbedaan signifikan kadar TnI dan hs-TnI berdasarkan derajat stenosis dengan $\mathrm{p}<0,001$. Kadar TnI dan hs-TnI pada subjek dengan CAD 3VD lebih tinggi secara signifikan dibandingkan derajat stenosis lainnya.

Hasil uji menunjukkan terdapat korelasi positif yang signifikan antara TnI terhadap derajat stenosis dengan nilai $r=0,707$, dimana semakin tinggi $\mathrm{TnI}$ semakin tinggi pula derajat stenosis $(\mathrm{p}<0,001)$. Besar korelasi diantara keduanya adalah $(0,707)^{2}=$ 0,499 atau 49,9\% (Gambar 1).

Selain itu terdapat korelasi positif yang signifikan antara hs-TnI terhadap derajat stenosis dengan nilai $r=0,877$, dimana semakin tinggi hs-TnI semakin tinggi pula derajat stenosis $(\mathrm{p}<0,001)$. Besar korelasi diantara keduanya adalah $(0,877)^{2}=0,769$ atau $76,9 \%$ (Gambar 2).
Hasil studi ini juga menunjukkan terdapat korelasi positif yang signifikan antara TnI dengan hs-TnI dengan nilai $\mathrm{r}=0,804$, dimana semakin tinggi TnI semakin tinggi pula hs-TnI $(\mathrm{p}<0,001)$. Besar korelasi diantara keduanya adalah $(0,804)^{2}=$ 0,646 atau 64,6\% (Gambar 3).

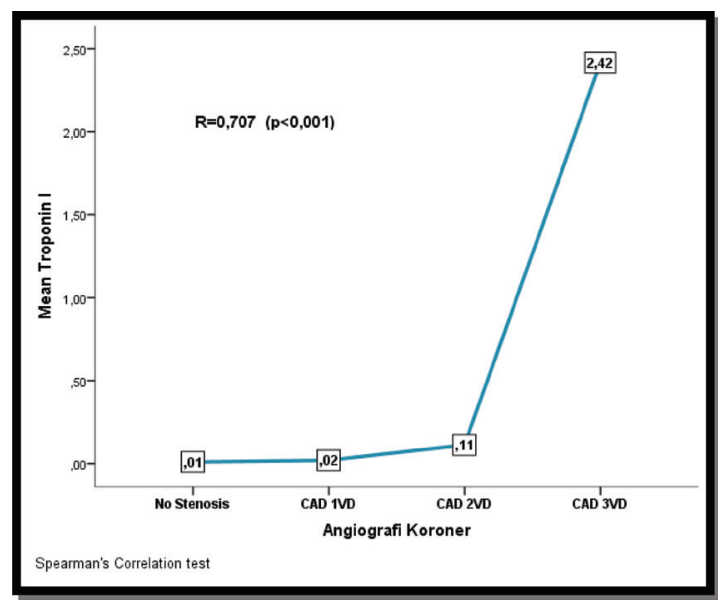

Gambar 1 Korelasi TnI dengan angiografi koroner

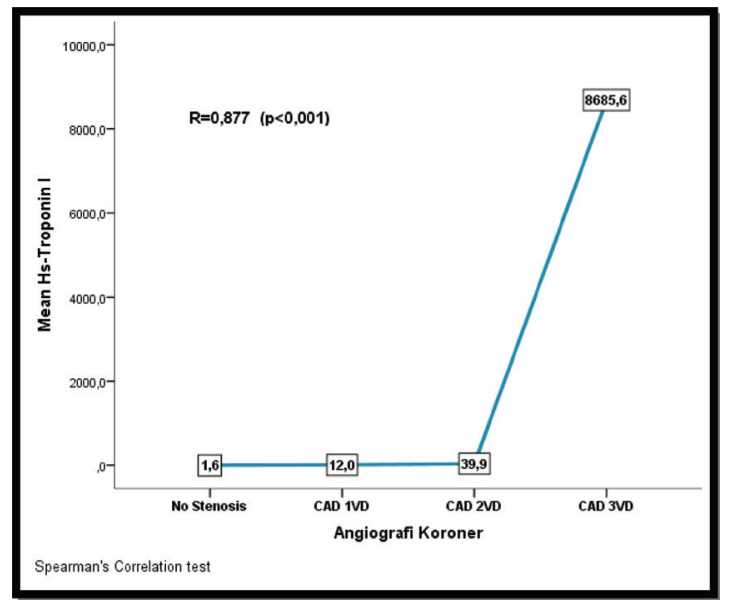

Gambar 2 Korelasi hs-TnI dengan angiografi koroner

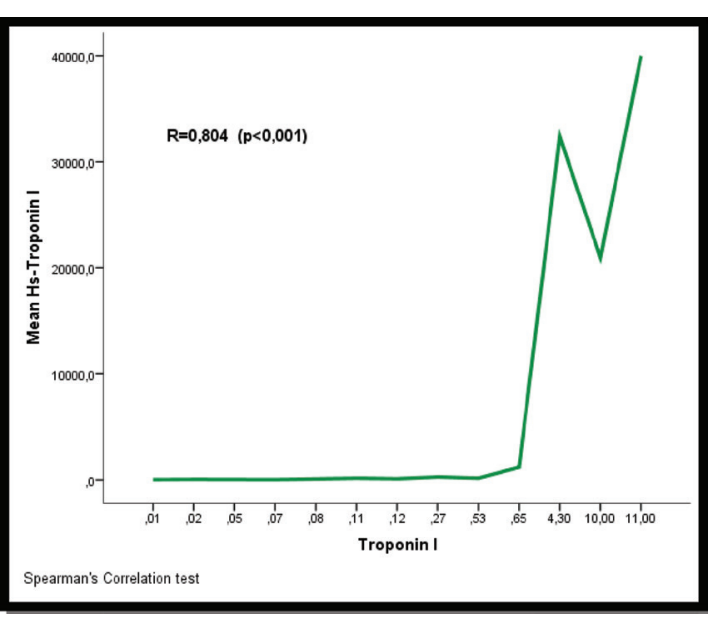

Gambar 3 Korelasi TnI dengan Hs-TnI 


\section{PEMBAHASAN}

Pada Tabel 1 didapatkan bahwa sebagian besar subjek dengan suspek CAD berjenis kelamin lakilaki. Hasil penelitian ini sejalan dengan penelitian yang dilakukan oleh Tahhan et al. (2018), yang mendapati bahwa $64 \%$ dari populasi subjek yang diteliti berjenis kelamin laki-laki. ${ }^{6}$ Tsioufis et al. (2018) juga menyimpulkan bahwa kejadian penyakit kardiovaskular dan kematian yang dikaitkan dengan aterosklerosis dua kali lebih tinggi pada laki-laki dibandingkan dengan perempuan pada usia 40-60 tahun. ${ }^{13}$ Observasi ini telah memunculkan hipotesis mengenai peran atheroprotektif hormon seks wanita. Estrogen dikaitkan dengan peningkatan high-density lipoprotein (HDL) dan penurunan tingkat low density lipoprotein (LDL), serta beragam efek antioksidan, vasoprotektif dan antitrombotik. Faktor kedua yaitu merokok yang didominasi oleh laki-laki ini telah lama ditetapkan sebagai faktor risiko yang dapat dicegah. Faktor ini berperan hingga 10\% dari semua kematian akibat penyakit kardiovaskular menurut World Health Organization (WHO). Asap rokok mengandung zat-zat berbahaya yang dapat menyebabkan penurunan aliran darah koroner dan pengiriman oksigen miokard. Asap rokok juga memiliki efek buruk pada lipid, tekanan darah, menimbulkan resistensi insulin dan menyebabkan perubahan biokimia pada endotelium.

Dari Tabel 1 dapat dilihat bahwa pasien dengan suspek CAD paling banyak ditemukan pada kelompok umur 50-69 tahun. Selain itu terdapat kecenderungan peningkatan $\mathrm{CAD}$ mulai dari

Tabel 1 Karakteristik subjek penelitian berdasarkan umur, jenis kelamin dan angiografi koroner $(\mathbf{n}=\mathbf{3 1})$

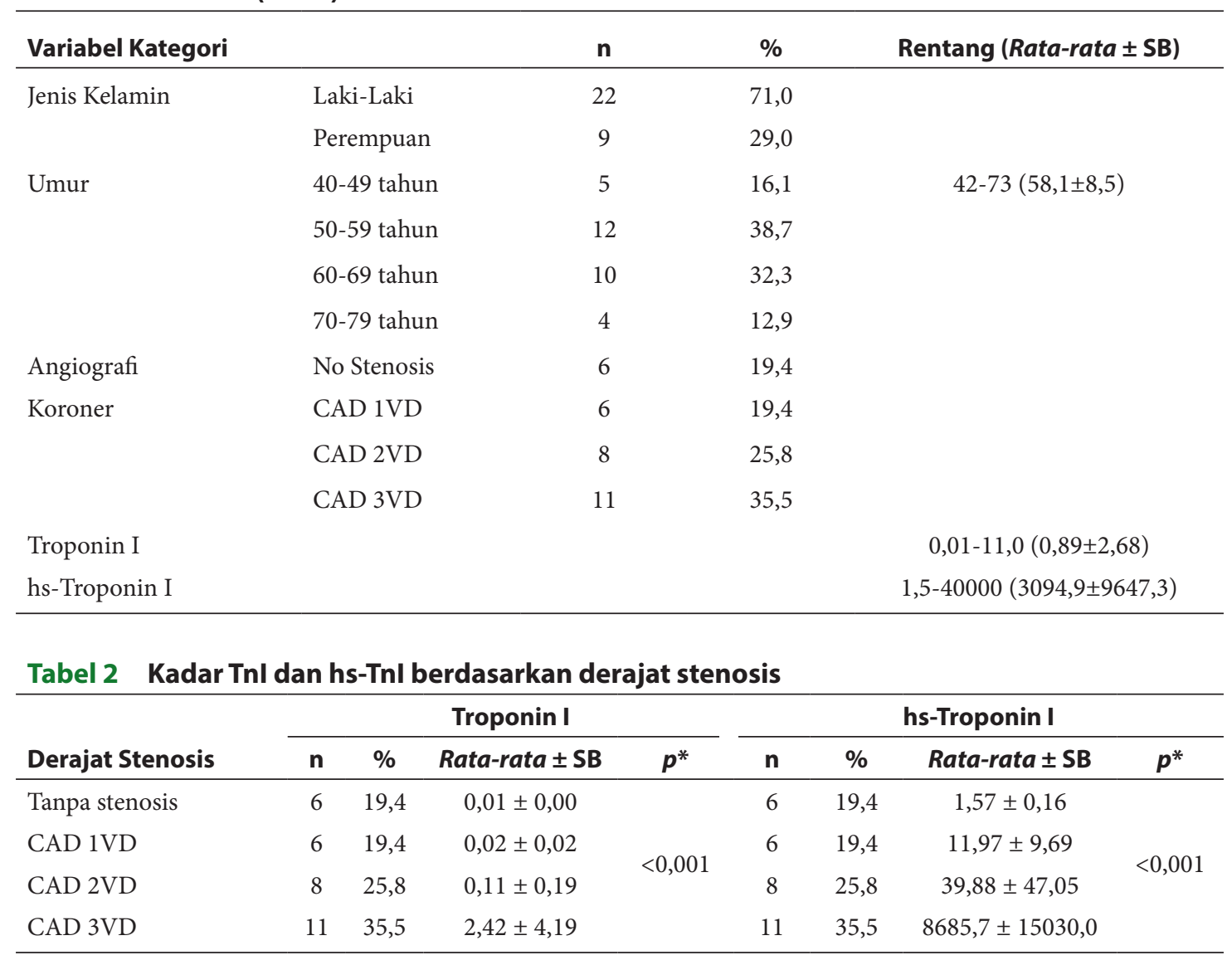

${ }^{\star}$ Kruskall-Wallis test

Tabel 3 Korelasi Tnl dan hs-Tnl dengan derajat stenosis

\begin{tabular}{lcccccc}
\hline & \multicolumn{2}{c}{ Hs-Troponin I } & & \multicolumn{2}{c}{ Derajat Stenosis } \\
\cline { 2 - 3 } \cline { 5 - 6 } Variabel & $\mathbf{r}$ & $p^{*}$ & & $\mathbf{r}$ & $p^{*}$ \\
\hline Troponin I & 0,804 & 0,000 & & 0,707 & 0,000 \\
Hs-Troponin I & & & & 0,877 & 0,000 \\
\hline
\end{tabular}

*Spearman's correlation test 
umur 50-59 tahun sebesar 2 kali lipat dibanding pada kelompok umur di bawahnya. Hasil penelitian ini sejalan dengan hasil Riskesdas tahun 2013 yang menunjukkan prevalensi penyakit jantung koroner yang terdiagnosis dokter melalui anamnesis meningkat seiring dengan bertambahnya umur. Hasil Riskesdas menunjukkan bahwa prevalensi tertinggi ditemukan pada kelompok umur 65 -74 tahun. ${ }^{3}$ Menurut Tsioufis et al. (2018), umur adalah faktor risiko kuat yang tidak dapat dimodifikasi pada penyakit-penyakit kardiovaskular. ${ }^{13}$ Di sisi lain, penuaan arteri identik dengan arteriosklerosis, yaitu proses degeneratif yang berkaitan dengan usia yang meningkatkan kekakuan pada lumen arteri. Menurut Diamond dan Forrester, diagnosis CAD tetap memungkinkan pada pasien yang memiliki gejala dan faktor risiko, meskipun tampaknya terlalu dini untuk memprediksi kemungkinan CAD setelah penilaian riwayat klinis dan pemeriksaan fisik. Dengan menggabungkan data dari studi angiografi terlihat jelas bahwa pemeriksaan klinis, penilaian nyeri, usia, dan jenis kelamin adalah prediktor signifikan dari CAD.

Tabel 2 memperlihatkan bahwa terdapat perbedaan signifikan kadar TnI dengan derajat stenosis pada angiografi koroner pasien suspek CAD $(\mathrm{p}<0,001)$. Hasil uji menunjukkan TnI pada CAD 3VD lebih tinggi secara signifikan dibandingkan derajat stenosis lainnya. Pengujian hs-TnI juga menunjukkan hasil yang signifikan $(\mathrm{p}<0,001)$, dimana kadar yang lebih tinggi berhubungan dengan tingkat keparahan CAD yang lebih besar, yang terkonfirmasi dari jumlah arteri koroner yang menyempit. Hasil ini sejalan dengan penelitian Tahhan et al. (2018) yang menyelidiki hubungan antara hsTnI dengan derajat CAD berdasarkan pemeriksaan angiografi. Dan dari hasil penelitian tersebut disimpulkan bahwa tingkat hs-TnI yang lebih tinggi berhubungan dengan risiko aterosklerosis yang lebih besar. Tingkat hs-TnI juga merupakan prediktor signifikan untuk insidensi mortalitas, kematian kardiovaskular, infark miokard, revaskularisasi, dan penyakit jantung yang dirawat inap. ${ }^{6}$ Peningkatan kadar hs-TnI di sirkulasi belum tentu berimplikasi terhadap kematian sel miokard. Peningkatan kebutuhan metabolisme jantung dapat menyebabkan pembelahan dan pelepasan hs-TnI. Selain itu, mikrotrauma yang disebabkan oleh lepasnya trombus di pembuluh darah koroner yang kecil bisa menjadi potensi penyebab meningkatnya kadar hs-TnI dan mungkin menjadi penjelasan bahwa CAD yang lebih parah dikaitkan dengan tingkat hsTnI yang lebih tinggi. Penelitian Omland et al. (2013) di Amerika juga menyimpulkan bahwa peningkatan kadar hs-TnI berhubungan dengan kejadian kerusakan otot jantung atau gagal jantung pada pasien dengan CAD karena beratnya derajat stenosis yang terjadi akan semakin mengurangi suplai oksigen ke organ sehingga risiko terjadi kerusakan pada otot jantung lebih cepat.

Pada Tabel 3 dapat dilihat bahwa TnI dan hs-TnI memiliki korelasi positif dengan derajat stenosis pada pemeriksaan angiografi koroner. Hubungan TnI dan derajat stenosis memiliki nilai korelasi kuat $(\mathrm{r}=0,707)$, hubungan hs-TnI dan derajat stenosis memiliki nilai korelasi kuat $(\mathrm{r}=0,877)$, dan hubungan TnI dengan hs-TnI juga memiliki nilai korelasi kuat $(\mathrm{r}=0,804)$. Hal tersebut menunjukkan semakin tinggi kadar TnI atau hs-TnI, semakin tinggi pula derajat stenosisnya. Penelitian Iribarren et al. (2016) di California yang juga menyimpulkan bahwa tes troponin dapat menyampaikan informasi prognostik tambahan untuk insiden CAD di antara orang dewasa lanjut usia yang tidak bergejala. ${ }^{12}$

\section{SIMPULAN}

Studi ini menunjukkan bahwa kasus CAD lebih banyak terjadi pada laki-laki dengan rentang umur paling banyak pada usia 50-69 tahun. Terdapat hubungan yang kuat antara TnI dan hs-TnI terhadap derajat stenosis. Peningkatan kadar TnI dan hs-TnI dapat memberikan gambaran beratnya derajat stenosis pada CAD. Serta pemeriksaan, Hs-TnI lebih baik dibandingkan TnI dalam menentukan derajat stenosis pada CAD.

\section{ETIKA PENELITIAN}

Studi ini telah mendapat persetujuan etik sebelum dilakukan dari Komisi Etik, Fakultas Kedokteran Universitas Hasanuddin, Makassar.

\section{KONFLIK KEPENTINGAN}

Tidak terdapat konflik kepentingan dalam penulisan hasil penelitian ini.

\section{PENDANAAN}

Studi ini dibiayai oleh penulis sendiri tanpa keterlibatan grant, sponsor, maupun sumber pendanaan lainnya.

\section{KONTRIBUSI PENULIS}

Seluruh penulis memiliki kontribusi yang sama dalam penulisan laporan penelitian ini dari persiapan manuskrip, analisis data, maupun penyusunan laporan akhir. 


\section{DAFTAR PUSTAKA}

1. Benjamin EJ, Blaha MJ, Chiuve SE, Cruhman M, Das SR et al. Heart Disease and Stroke Statistics-2017 update: a report from the American Heart Association. Circulation. 2017; 35(10):e146-e603.

2. Beltrame JF, Dreyer R and Tavella R. Epidemiology of of Coronary Artery Disease. In David Gaze (Ed.), Coronary Artery Disease - Current Concepts in Epidemiology, Pathophysiology, Diagnostics and Treatment. DOI: 10.5772/29030. 2013. Available from: https://www.intechopen.com/books/coronaryartery-disease-current-concepts-in-epidemiologypathophysiology-diagnostics-and-treatment/ epidemiology-of-coronary-artery-disease

3. Riset Kesehatan Dasar (Riskesdas). Badan Litbangkes, Depkes RI. Jakarta; 2013;91.

4. Cesar LA, Ferreira JF, Armaganijan D, Gowdak LH, Mansur Ap et al. Guidelines For Stabel Coronary Artery Disease. Arq Brass Cardiol. 2014;103(2 Supl 2):1-56.

5. Coldea LA, Cionca C and Lupu S. 2015. Coronary CT Angiography and the Napkin-ring Sign Indicates High-Risk Atherosclerotic Lessions. In Kaan Kirali (Ed.), Coronary Artery Disease: Assesment, Surgery, Prevention. 2015. DOI: 10.5772/61393. Available from: https://www.intechopen. com/books/coronary-artery-disease-assessment-surgeryprevention/coronary-ct-angiography-and-the-napkinring-sign-indicates-high-risk-atherosclerotic-lesions

6. Tahhan AS, Sandesara P, Hayek SS, Hammadah M, Alkhoder A et al. High-Sensitivity TroponinI Levels and Coronary Artery Disease Severity, Progression, and LongTerm Outcomes. J Am Heart Assoc. 2018;7:e007914.

7. Kumar R and Ahmad MI. High sensitive troponin as biomarker for coronary artery disease. J Clin Cardiolog. 2017;8:2.

8. Samsu N. Sensitivitas dan spesifisitas troponin T dan I pada diagnosis infark miokard akut. Maj Kedokt Indon. 2007;57(10):363-71.

9. Borren N, Angela HEM, and Ottervanger JP. Stop invasive coronary angiography as the gold standard for dignosis of stable angina. Interv Cardiol 2015;7(5):1-4.

10. Jomansyah MUA. Angiografi koroner. CDK-207. 2013;40(8):626-8.

11. Ford I, Anoop SV, Zhang R, McAllister, Stachan FE et al. High-Sensitivity Cardiac Troponin, Statin Therapy, and Risk of Coronary Heart Disease. Jounal of the American Collage of Cardiology. 2016;68(25): 2719.

12. Iribarren C, Chandra M, Rana JS, Hlatky MA, Fortmann SP et al. High-Sensitivity Cardiac Troponin I and Incident Coronary Heart Disease Among Asymptomatic Older Adults. Heart. 2016;102:1177-82.
13. Tsioufis C, Mantzouranis E, Kalos T, Konstantinidis D, Tousoulis D. Risk Factors of Atherosclerosis: Pathophysiological Mechanisms. In Dimitris Tousoulis, Coronary Artery Disease From Biology to Clinical Practice. Elsevier Inc. 2018.

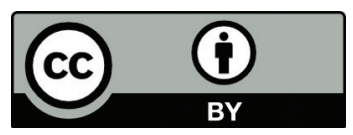

This work is licensed under a Creative Commons Attribution 